\title{
Experimental and Theoretical Characterization of Arsenite in Water: Insights into the Coordination Environment of As-O
}

\author{
Alejandro Ramírez-Solís ${ }^{\dagger}$, Rita Mukopadhyay $\ddagger$, Barry P. Rosen ${ }^{\ddagger}$, and Timothy L. \\ Stemmler ${ }^{*}, \neq$ \\ Depto. de Física, Facultad de Ciencias, Universidad Autónoma del Estado de Morelos, Av. \\ Universidad 1001, Cuernavaca, Morelos, 62210 Mexico, and Department of Biochemistry and \\ Molecular Biology, Wayne State University, School of Medicine, 540 E. Canfield Avenue, Detroit, \\ Michigan 48201
}

\begin{abstract}
Long-term exposure to arsenic in drinking water has been linked to cancer of the bladder, lungs, skin, kidney, nasal passages, liver, and prostate in humans. It is therefore important to understand the structural aspects of arsenic in water, as hydrated arsenic is most likely the initial form of the metalloid absorbed by cells. We present a detailed experimental and theoretical characterization of the coordination environment of hydrated arsenite. XANES analysis confirms As(III) is a stable redox form of the metalloid in solution. EXAFS analysis indicate, at neutral $\mathrm{pH}$, arsenite has a nearest-neighbor coordination geometry of approximately $3 \mathrm{As}-\mathrm{O}$ bonds at an average bond length of $1.77 \AA$, while at basic $\mathrm{pH}$ the nearest-neighbor coordination geometry shifts to a single short As-O bond at $1.69 \AA$ and two longer As-O bonds at $1.82 \AA$. Long-range ligand scattering is present in all EXAFS samples; however, these data could not be fit with any degree of certainty. There is no XAS detectable interaction between As and antimony, suggesting they are not imported into cells as a multinuclear complex. XAS results were compared to a structural database of arsenite compounds to confirm that a 3 coordinate As-O complex for hydrated arsenite is the predominate species in solution. Finally, quantum chemical studies indicate arsenite in solution is solvated by 3 water molecules. These results indicate $\mathrm{As}(\mathrm{OH})_{3}$ as the most stable structure existing in solution at neutral $\mathrm{pH}$; thus, ionic As transport does not appear to be involved in the cellular uptake process.
\end{abstract}

\section{Introduction}

Arsenic is classified as a carcinogen by the United States Environmental Protection Agency (EPA). ${ }^{1}$ Exposure to arsenic in drinking water is associated with increased risk of skin, kidney, lung, and bladder cancer. Chronic effects of arsenic in the water supply include skin hyperpigmentation and keratoses of the hands and feet that frequently progress to skin cancers. According to the National Resources Defense Council, millions of North Americans are consuming tap water every day that poses unacceptable cancer risks. In 1976 the EPA set the maximum contamination level (MCL) for arsenic at $50 \mu \mathrm{g} / \mathrm{L}$. The National Research Councils recommended a MCL of $10 \mu \mathrm{g} / \mathrm{L}$, which will be put into effect in the near future. Despite a considerable body of literature on arsenic biochemistry, ${ }^{2}$ very little is

\footnotetext{
(C) 2004 American Chemical Society

*Author to whom correspondence should be addressed. tstemmle@med.wayne.

†Universidad Autónoma del Estado de Morelos.

‡Wayne State University.
}

Supporting Information Available: Data regarding EXAFS model fitting analysis and structural simulations from Gaussian calculations. This material is available free of charge via the Internet at http://pubs.acs.org. 
known about the forms of inorganic arsenic present in solution under physiological conditions.

Arsenic is a semimetal or metalloid with two biologically important oxidation states, As(V) and $\mathrm{As}(\mathrm{III})$, and it is commercially available as the oxyarsenic acid $\left(\mathrm{H}_{3} \mathrm{AsO}_{4}\right)$ or as arsenous acid, also called arsenic trioxide $\left(\mathrm{As}_{2} \mathrm{O}_{3}\right)$. Arsenite in water has a $\mathrm{p} K_{\mathrm{a}}$ of 9.2 , and it has been speculated to exist as $\mathrm{As}(\mathrm{OH})_{3}$ in the hydrated form, though this has never been firmly characterized. ${ }^{3}$ The elevated $\mathrm{p} K_{\mathrm{a}}$ is relevant for the type of transport system that catalyzes uptake of the pentavalent and trivalent forms of arsenic. Cellular uptake of inorganic arsenate $(\mathrm{As}(\mathrm{V}))$ is almost always performed via phosphate transporters. ${ }^{2}$ However, it has only recently been recognized that uptake of As(III) occurs via channels for neutral molecules, ${ }^{3,4}$ indicating that $\mathrm{As}(\mathrm{OH})_{3}$ or other related species could be the common form of arsenite in water. Furthermore, bacterial arsenite export is stimulated in the presence of antimony, suggesting that a possible nucleation between the different metalloids (i.e. a AsSb complex) might also be possible in solution. ${ }^{5}$ Because of the biological consequences, it is very important to understand the solution forms of inorganic arsenic compounds. We therefore present a detailed theoretical and experimental characterization of the coordination environment of hydrated As compounds to provide a basic structural understanding of how the metalloid exists in solution.

Two complementary methods were used to identify the coordination environment of arsenite in water. X-ray absorption spectroscopy (XAS) was used to identify the stable oxidation state of hydrated arsenite and determine the nearest-neighbor coordination environment of arsenite under a variety of solution conditions. XAS results were compared to a structural database of arsenite compounds to identify probable coordination geometries for the metalloid in solution. Finally, quantum chemical studies were carried out to obtain a complete understanding of how As(III)-O interactions govern the solution forms of hydrated arsenic. When combined, these investigations provide a basic understanding of the molecular structure of solvated arsenite. These results have direct implications into the reactive form of the metalloid that gets imported by cells causing arsenic toxicity. In addition, our results may influence current methods being developed for removing the metalloid from groundwater through filtration.

\section{Experimental Section}

\section{Sample Preparation}

A series of samples were prepared for XAS studies to test the effect of $\mathrm{pH}$ on the coordination geometry of solubilized arsenite, as well as to test for nucleation between the As and $\mathrm{Sb}$ metalloid atoms in mixed solutions. All samples were prepared by dissolving $\mathrm{AsNaO}_{2}$ (Sigma) in unbuffered water adjusted to $\mathrm{pH}$ of 7.0 or 11.8 using concentrated sodium hydroxide. Arsenite samples with antimonite were prepared using $5 \mathrm{mM} \mathrm{K}_{2^{-}}$ $\mathrm{Sb}_{2}$ tartrate $3 \mathrm{H}_{2} \mathrm{O}$ (tartrate is $\mathrm{C}_{8} \mathrm{H}_{4} \mathrm{O}_{12}$ ) (Sigma) as the antimony salt. Individual samples and their metalloid concentrations are outlined in Table 1.

\section{X-ray Absorption Spectroscopy}

XAS samples were transferred into Lucite cells wrapped with Kapton tape using a Hamilton syringe and immediately flash-frozen by dropping samples into liquid nitrogen. XAS measurements were performed on reproducible independent samples. XAS data were collected at beamline 7-3 at the Stanford Synchrotron Radiation Laboratory (SSRL) using a $\mathrm{Si}-(220)$ double-crystal monochromator detuned $50 \%$ for harmonic rejection. Fluorescence excitation spectra were recorded using a 30-element Ge solid-state array detector. Samples were maintained at $10 \mathrm{~K}$ using an Oxford Instruments continuous-flow liquid-helium cryostat. Spectra were measured using $5 \mathrm{eV}$ steps in the preedge, $0.25 \mathrm{eV}$ steps in the edge 
(11 850-11 $900 \mathrm{eV}$ ), and $0.05 \AA^{-1}$ increments in the extended X-ray absorption fine structure (EXAFS) region out to a $k$ range of 15.5 , integrating from 1 to $20 \mathrm{~s}$ in a $k^{3}$ weighted manner for a total scan length of $30 \mathrm{~min}$. X-ray energies were calibrated by simultaneous measurement of an As(0) foil absorption spectrum, assigning the first inflection point as $11867 \mathrm{eV}$. Each channel of each scan was examined for glitches prior to averaging, and spectra were closely monitored for photoreduction. Spectra represent the average of 3 scans.

XAS data were analyzed according to a previously published protocol. ${ }^{6}$ Data were converted to $k$-space using an $E_{0}$ of $11885 \mathrm{eV}$, and the EXAFS were $k^{3}$ weighted and truncated between 1.0 and $15.0 \AA^{-1}$ for filtering purposes and Fourier transformed. Fitting analysis was performed on both Fourier-filtered and raw/unfiltered data. The best-fit bond lengths $(R)$, coordination numbers $(\mathrm{CN})$, and Debye-Waller factors $\left(\sigma^{2}\right)$ listed in Table 2 were determined from fitting Fourier-filtered $(R)$ 1.0-3.4 $\AA$ ) data. Fits to both Fourier-filtered and unfiltered data gave equivalent structural parameters. EXAFS data were fit using theoretical amplitude and phase functions calculated, using Feff 7.0, for possible As-O interactions at 2.00 and $2.40 \AA$, As-S interactions at 2.25 and $2.40 \AA$, and As-As or As-Sb interactions at $2.40 \AA$. The calibrated scale factor $(0.98)$ and $E_{0}(-10.0 \mathrm{eV})$ were held constant during all fits. These parameters were calibrated by fitting EXAFS data for published model control spectra for As(glutathione) $)_{3}$; control XAS spectra for As(glutathione) $)_{3}$ and $\mathrm{Na}_{3} \mathrm{AsO}_{4}$ were previously published and kindly provided by the Penner-Hahn laboratory. ${ }^{7}$ Calibrated fits to model spectra are included as Supporting Information. During the fitting analysis, coordination numbers were fixed at half-integer values while bond lengths and Debye-Waller factors were allowed to vary freely. The mean square deviation between data and fit, corrected for the number of degrees of freedom, was used to determine the best simulation, as well as for justifying the addition of supplementary interactions to the simulation. ${ }^{8}$

\section{Cambridge Structural Database Analysis}

Small-molecule As-ligand structural correlations were obtained by searching the Cambridge Structural Database (CSD) library using the program ConQuest version $1.5 .^{9}$ The oxidation state of arsenic was held to As(III) in each search, and the coordination number was held constant at integer values. Arsenite-ligand crystallized model systems within the CSD analysis were selected for bond length statistical analysis according to the following criteria: (a) The arsenic oxidation state was clearly As(III). (b) Molecules with As-O bonds had at least 2 oxygen atoms bound to arsenic. (c) There was no multinuclear species between As(III) and metals/metalloids other than As or Sb. Finally, (d) complexes with aromatic, aliphatic, sulfur, or phosphorus containing ligands were excluded. Bond statistics were analyzed using the program Vista.

\section{Quantum Chemical Calculations}

Density functional theory (DFT-) -based calculations were done for several model molecules considered as possible candidates for explaining our experimentally observed As-O coordination environment data. All calculations used the energy-adjusted Stuttgart relativistic effective core potentials (RECP) for As, along with its optimized Gaussian basis set [As]. ${ }^{10}$ This RECP includes all the main scalar relativistic effects (Darwin and massvelocity) which are important for heavy elements such as As. It uses a nickel-type core and leaves 5 active valence electrons. For oxygen and hydrogen, the standard 6-31G* and 6$311+\mathrm{G}^{* *}$ basis sets were used. We used the standard B3LYP exchange-correlation functional as programmed in the Gaussian98 code. ${ }^{11}$ Additional ab initio single reference Möller-Plesset second-order perturbational (MP2) calculations were performed on theoretical structures that matched our experimental values. 


\section{Results}

\section{X-ray Absorption Near-Edge Spectroscopy (XANES)}

XANES spectra for all samples in Table 1, as well as our $\mathrm{As}(\mathrm{V})$ control from $\mathrm{Na}_{3} \mathrm{AsO}_{4}$, are shown in Figure 1. The first inflection points of the As edges for all samples except the $\mathrm{As}(\mathrm{V})$ control occur at approximately $11870 \mathrm{eV}$, indicating that every sample except $\mathrm{Na}_{3} \mathrm{AsO}_{4}$ exist in the As(III) oxidation state. Edges features for all As(III) samples except $\mathrm{As}(\mathrm{pH} 12)$ are very similar, suggesting minimal structural rearrangement in the As-ligand coordination sphere as a result of the addition of $\mathrm{Sb}(\mathrm{III})$. However, on the basis of structural changes in the edge feature at $11875 \mathrm{eV}$ and the absence of a peak at $11887 \mathrm{eV}$, there is clearly a $\mathrm{pH}$ effect on the As(III) coordination environment.

\section{EXAFS Data and Fitting Analysis}

Raw EXAFS and the Fourier transforms of the As EXAFS for all samples are displayed in Figure 2. For every sample, the spectral features in the Fourier transform consist of a single intense low bond length feature at below the phase-shifted value of $1.4 \AA$ (actual value approximately $1.8 \AA$ ) and a low-intensity long-range feature centered at a phase-shifted value of $2.3 \AA$ (actual value approximately $2.7 \AA$ ). Spectral features are identical for all samples except As(pH12), which has a shift in the As nearest-neighbor signal toward lower bond length and toward increased disorder.

A summary of the EXAFS best-fit analysis results is given in Table 2 while simulations of the best fits are shown in Figure 2. Experimental data were simulated using multiple models that incorporate either the progressive addition of scattering environments or the variation of the scattering atom within the ligand shell. Within the analysis for each sample, each row represents the best-fit values for that model. Best fits were determined by having the lowest $F^{\prime}$ value and a reasonable Debye-Waller factor below $5 \times 10^{-3} \AA^{2}$. Note that the scattering atom and the coordination numbers were systematically varied but not allowed to freely float within the simulation. Progressive addition of additional scattering environments was justified by a decrease in $F^{\prime}$ value. For each sample, the As nearest-neighbor ligand environment was initially fit to obtain the identity of atoms directly coordinated to the metal and ligand-metal geometry. The best simulation of the $1.8 \AA$ features for all spectra except As(pH12) was with an oxygen-based ligand environment consisting of a single oxygen ligand environment at ca. $1.78 \AA$ and coordination number of 3.5 for every sample. In the case of $\mathrm{As}(\mathrm{pH} 12)$, the As nearest-neighbor ligand environment was best fit with two different As-O interactions at $1.69 \AA$ (a coordination number of 1.0) and $1.82 \AA$ (a coordination number of 2.5), as judged by the decrease in $F^{\prime}$ value between going from a single ligand shell fit to a 2 shell fit. Attempts were made to fit long-range As-ligand scattering (at approximately $2.7 \AA$ ) with either sodium, arsenic, or oxygen scattering. In every case, including a ligand environment that consisted of long-range As-As or As-Na scattering proved unsuccessful, while simulations including oxygen scattering at ca. $2.7 \AA$ provided a slightly improved fit on the basis of the decrease in $F^{\prime}$.

\section{Cambridge Structural Database Analysis}

To address the question of what As coordination number $(3,3.5$, or 4$)$ best fits our highly accurate EXAFS As-O bond lengths or if an oxygen bridging As-O-As or As-O-Sb complex would fit our EXAFS data, we performed a detailed analysis of all crystallographically characterized As(III) complexes whose structures have been posted in the Cambridge Structural Database (CSD). A CSD search was made to identify standard bond distances in both three- and four-coordinate As(III) complexes under a variety of conditions (i.e., those containing As- $\mathrm{O}, \mathrm{As}-\mathrm{As}$, and As-Sb coordination in the nearestneighbor environment and also through bridging As-O-As and As-O-Sb systems). As 
shown in Table 3, typical three-coordinate As-O complexes have an average As-O bond length of $1.77 \pm 0.03 \AA$, while four-coordinate As-O bonds are at $1.81 \pm 0.02 \AA$. Numerous examples of both three- and four-coordinate As-As complexes were reported at average bond lengths of $2.43 \pm 0.06$ and $2.45 \pm 0.02 \AA$, respectively, while a single As-Sb complex was reported to be four-coordinated at a bond length of $2.66 \AA$. Bridging As-O-As systems were identified for three-coordinate arsenite only, with an average As-O bond of $1.78 \pm 0.01$ $\AA$ and a long-range As $\bullet \bullet$ As distance of $3.22 \pm 0.03 \AA$.

\section{Quantum Chemical Studies}

Since our goal with these calculations is to obtain possible As-O coordination environments that can explain the rather well-defined $1.78 \AA$ observed peaks in the pH ) 7.0 samples, the structures of all these As-O complexes were simulated in the presence of up to three water molecules in the first solvation shell. The optimized structures were characterized as true minima in the potential energy surface by performing a vibrational analysis. No imaginary frequencies were found for any of the optimized structures. Unfortunately, to the best of our knowledge, no previous ab initio or DFT-based calculations have ever been reported before for this type of arsenic-containing systems, so we lack theoretical information to compare our results.

For the triply charged As ion, we studied the hexahydrated cation and obtained, as expected, a rather rigid tetragonal bipyramid. A neutral $\mathrm{As}(\mathrm{OH})_{3}$ molecule, which we believe is the stable form of hydrated As(III) on the basis of our EXAFS and CSD results, was studied using up to three solvating water molecules; however, it must be said that the number of degrees of freedom for the $\mathrm{As}(\mathrm{OH})_{3}$ molecule solvated with 3 water molecules is already 42 , so the accurate search for minimum energy structures becomes a formidable task for 4 or more water molecules. For this case, we ran more than a dozen optimizations with different starting geometries for the 3 solvating water molecules. We found three very different minima which span a $5 \mathrm{kcal} / \mathrm{mol}$ range, and of course, we do not claim to have found all structures or the lowest energy structure. The calculations were done on the following species: $\left[\mathrm{As}-\left(\mathrm{H}_{2} \mathrm{O}\right)_{6}\right]^{3+} ;(\mathrm{OH})_{2} \mathrm{As}-(\mathrm{OH})_{2} ;(\mathrm{OH})_{2} \mathrm{As}-\mathrm{O}-\mathrm{As}(\mathrm{OH})_{2} ;\left[\mathrm{As}(\mathrm{OH})_{4}\right]^{+} ; \mathrm{As}(\mathrm{OH})_{3} \cdots$ $\mathrm{H}_{2} \mathrm{O} ; \mathrm{As}(\mathrm{OH})_{3} \cdots\left(\mathrm{H}_{2} \mathrm{O}\right)_{2} ; \mathrm{As}(\mathrm{OH})_{3} \cdots\left(\mathrm{H}_{2} \mathrm{O}\right)_{3}$. The As-As and As-O-As complexes were included to have an idea on the longer range As-O coordination that is responsible for the $2.7 \AA$ peak observed in the XANES spectra.

Optimized As-O distances for all the individual and solvated species we used as models are presented in Table 4. All other optimized geometrical parameters are available upon request in the form of a $z$-matrix for every species; however, these are not relevant for our present purpose. These calculated distances are in very good agreement with the $1.78 \AA$ experimentally EXAFS determined As-O nearest-neighbor distance.

Single reference second-order Möller-Plesset perturbational (MP2) calculations were done to characterize the lowest energy B3LYP-optimized trihydrated $\mathrm{As}(\mathrm{OH})_{3}$ moiety. These MP2 results showed that the DFT-B3LYP results, which produced a single hydrogenbonded complex, are inaccurate. However, this is not surprising because it is well-known that DFT-based calculations cannot properly deal with the delicate electronic correlation effects that lead to weakly bound complexes. Optimized MP2/6-311+G** $x y z$ coordinates for the $\mathrm{As}(\mathrm{OH})_{4}+\bullet \bullet\left(\mathrm{H}_{2} \mathrm{O}\right)_{4}$ complex appear in Table 5. Optimized MP2 geometries for the tri- and tetrahydrated complexes are supplied in the Supporting Information for this article.

\section{Discussion}

Cellular import of arsenic is surely controlled in part by the bioavailability of the metalloid and by the metalloid's ligand geometry in solution. An understanding of how the metalloid 
behaves in solution provides insight into how it is pumped into the cells. This study illustrates the coordination environment of As(III) in water and provides a basic understanding of the interaction (or lack of apparent interaction) between arsenic and antimony in solution.

XANES spectra show that the oxidation state of As(III) in solution is maintained at neutral and high $\mathrm{pH}$, and the addition of antimony salts does not perturb the metalloids redox properties. Furthermore, the similarity of the edges between neutral $\mathrm{pH}$ arsenite in the presence and absence of antimony salts indicates there is no appreciable perturbation of the arsenite's coordination geometry when antimony is present. Finally, structural differences in the edges between neutral and high $\mathrm{pH}$ arsenite indicate that a significant structural change in As coordination geometry results from the elevation of the $\mathrm{pH}$.

The nearest-neighbor coordination environment of solubilized As(III) at neutral $\mathrm{pH}$ is constructed completely of oxygen ligands. When XAS data and CSD search results are combined, they create a picture of a three-coordinate As-O system only, where the protonation state of the oxygens are unknown, but presumably the oxygens are hydroxides to counterbalance the As(III) charge. The experimental results fit the theoretical distances predicted for three-coordinate As-OH, indicating that the protonation state of the bound oxygens are in fact all singly protonated and the energetically favorable first shell coordination environment is three-coordinate.

It has been suggested that As(III) in solution may form a direct As-As coordination as the active species for cellular import and export. ${ }^{5}$ It has been shown that bacterial As(III) export is enhanced in the presence of antimony, and this suggests a possible direct coordination between the different metalloids that might displace any multinuclear As-As interaction. Our data indicate, however, that there is no appreciable As-As interaction in solution, on the basis of the lack of As-As scattering in the EXAFS of the neutral samples and that the B3LYP (DFT) calculations, performed on the formation of an $(\mathrm{OH})_{2} \mathrm{As}-\mathrm{As}(\mathrm{OH})_{2}$ species, found it energetically unfavorable by more than $35 \mathrm{kcal} / \mathrm{mol}$, neglecting the solvation effects of all species in both sides. While the lack of a direct As-As interaction (or As-Sb in the antimony samples) does not conclusively state that such an interaction does not exist, the fact that the As-O bond lengths and coordination numbers from EXAFS exactly match the As- $\mathrm{O}_{3}$ coordination of crystallographically characterized models indicates that in fact no As-As (or As-Sb) direct ligation is present in these samples. Furthermore, the presence of antimony has no effect on the As coordination geometry, again indicating there is no detectable As-Sb interaction in solution when arsenite is in the presence of antimonite within our data. Thus, it again seems that an As- $(\mathrm{OH})_{3}$ moiety is the most dominant species in solution.

Natural questions that arise when one observes the long-range scattering (i.e. > 2.65 $\AA$ ) in the Fourier transforms of the EXAFS data are the following: Are these scattering features real, and if they are, what are they due to? Despite several efforts, we could not fit definitively the long-range scattering in the EXAFS, although we were able to get a partial improvement in our fits when an As $\bullet \bullet O$ interaction was introduced. The fact that coordination numbers for this ligand environment are low may suggest that arsenite has either one long-range ligand bound, a mixture of the same ligand type at multiple bond lengths, or different types of ligands that destructively dampen the scattering signal. One possibility would be that $\mathrm{As}(\mathrm{OH})_{3}$ induces some kind of long-range order on its second and third coordination shells. However, the dipole moment of $\mathrm{As}(\mathrm{OH})_{3}$ is $1.34 \mathrm{D}$, which may be too low to induce order beyond the first hydration shell. This hypothesis can be tested by performing classical or quantum molecular dynamics calculations on this system, a long and computationally demanding work that remains to be done in the future. The long-range 
scattering contributes minimally to the total scattering, and the average bond lengths for fits in this environment (ca. 2.65 $\AA$ ) is inconsistent with distances seen for bridging As-O-As systems; As••• As interactions in oxygen-bridged systems are on average at $3.22 \AA$, as shown in Table 3. Therefore, the scattering at $2.65 \AA$ is most consistent with one or more weakly coordinated water molecules. Theoretically calculated bond distances for an $\mathrm{As}(\mathrm{OH})_{3} \bullet 3 \mathrm{H}_{2} \mathrm{O}$ complex (one short water at ca. $2.7 \AA$ and two longer distance waters) most closely match the experimentally determined As-O long range distances. Therefore, these results indicate that at neutral $\mathrm{pH}$ the hydration sphere of arsenite in solution is most closely described as $\mathrm{As}^{\mathrm{III}}(\mathrm{OH})_{3} \cdot 3 \mathrm{H}_{2} \mathrm{O}$.

It is still possible that a multinuclear As complex with alternating As-O-As interactions exist in solution and we simply cannot detect the As••• As interaction. The crystallographically characterized $\mathrm{As}_{4} \mathrm{O}_{6}$ complex is constructed of alternating As-O-As bonds with an average As-O bond length (1.82 $\AA$ ); this value is however $0.05 \AA$ longer than the As-O distance we observe for our samples at neutral $\mathrm{pH} .^{11}$ The As $\bullet \bullet$ As interatomic distance $(3.23 \AA)$ in this complex is also dramatically longer than any long-range fits we obtained for our EXAFS data. Therefore, while we cannot exclude such a complex may also exist in solution, on the basis of the data it seems unlikely that this is the major species under investigation in our samples.

At high $\mathrm{pH}$, the arsenite hydration environment is clearly distinct from all neutral $\mathrm{pH}$ samples. The nearest-neighbor As-O scattering environment is best described by two As-O ligand interactions, one at a short As-O distance of $1.69 \AA$ and two longer As-O interactions at $1.82 \AA$. These data are inconsistent with an increase in coordination at the As nearestneighbor center (for example to $\mathrm{As}(\mathrm{OH})_{4}{ }^{-}$) since the average coordination number is unchanged between neutral and high $\mathrm{pH}$ samples and the fact that there are two distinct As$\mathrm{O}$ distances in the high $\mathrm{pH}$ sample. The most likely explanation for the change in As-O coordination would be the deprotonation of one of the bound hydroxides, generating the shorter As-O bond and causing the remaining As-O bond lengths to slightly increase. Changes in the nearest-neighbor coordination geometry are however unrelated to the longrange signal, as the average Asø• O distances between the high-pH and neutral samples are very similar.

\section{Conclusions}

Since hydrated arsenic is most likely the initial form of the metalloid absorbed by cells, it is therefore crucial that we understand the structural aspects of arsenic in water. Our results indicate that, at neutral $\mathrm{pH}, \mathrm{As}(\mathrm{OH})_{3}$ is the most stable structure existing in solution. We therefore suggest that As- $(\mathrm{OH})_{3}$ is the active form of the metalloid which is subject to cellular uptake. Thus, As transport seems to not involve an ionic form or a multinuclear As form of the metalloid that is brought into cells.

\section{Acknowledgments}

A.R.-S. acknowledges support from the CONACYT Project 34673-E and FOMES2000-SEP through project "Cómputo científico" for unlimited CPU time on the IBM-p690 32-processor supercomputer at UAEM. Portions of this research were carried out at the Stanford Synchrotron Radiation Laboratory, a national user facility operated by Stanford University on behalf of the U.S. Department of Energy, Office of Basic Energy Sciences. The SSRL Structural Molecular Biology Program is supported by the Department of Energy, Office of Biological and Environmental Research, and by the National Institutes of Health, National Center for Research Resources, Biomedical Technology Program. This work was supported by NIH Grants ES10344, AI43428, GM55425, and GM52216 to B.P.R. and the American Heart Association Grant 0130527Z to T.L.S. XAS spectra for As(glutathione) 3 and $\mathrm{Na}_{3} \mathrm{AsO}_{4}$ were kindly provided by Jim Penner-Hahn and Craig McClure (University of Michigan, Ann Arbor, MI). 


\section{References}

1. Smith AH, Hopenhayn-Rich C, Bates MN, Goeden HM, Hertz-Picciotto I, Duggan HM, Wood R, Kosnett MJ, Smith MT. Environ Health Perspect. 1992; 97:259-67. [PubMed: 1396465]

2. Rosen BP. FEBS Lett. 2002; 529:86-92. [PubMed: 12354618]

3. Liu Z, Shen J, Carbrey JM, Mukhopadhyay R, Agre P, Rosen BP. Proc Natl Acad Sci USA. 2002; 99:6053-8. [PubMed: 11972053]

4. Sanders OI, Rensing C, Kuroda M, Mitra B, Rosen BP. J Bacteriol. 1997; 179:3365-7. [PubMed: 9150238]

5. Kuroda M, Dey S, Sanders OI, Rosen BP. J Biol Chem. 1997; 272:326-31. [PubMed: 8995265]

6. Lieberman RL, Shrestha DB, Doan PE, Hoffman BM, Stemmler TL, Rosenzweig AC. Proc Natl Acad Sci USA. 2003; 100:3820-5. [PubMed: 12634423]

7. Farrer BT, McClure CP, Penner-Hahn JE, Pecoraro VL. Inorg Chem. 2000; 39:5422-23. [PubMed: 11154553]

8. Riggs-Gelasco PJ, Stemmler TL, Penner-Hahn JE. Coord Chem ReV. 1995; 114:245-86.

9. Cambridge Structural Database ConQuest 1.5. Cambridge Crystallographic Data Centre; Cambridge, U.K: 2002.

10. Bergner A, Dolg M, Kuechle W, Stoll H, Preuss H. Mol Phys. 1993; 80:1431.

11. Frisch, MJ.; Trucks, GW.; Schlegel, HB.; Scuseria, GE.; Robb, MA.; Cheeseman, JR.; Zakrzewski, VG.; Montgomery, JJA.; Stratmann, RE.; Burant, JC.; Dapprich, S.; Millam, JM.; Daniels, AD.;

Kudin, KN.; Strain, MC.; Farkas, O.; Tomasi, J.; Barone, V.; Cossi, M.; Cammi, R.; Mennucci, B.; Pomelli, C.; Adamo, C.; Clifford, S.; Ochterski, J.; Petersson, GA.; Ayala, PY.; Cui, Q.;

Morokuma, K.; Rega, N.; Salvador, P.; Dannenberg, JJ.; Malick, DK.; Rabuck, AD.;

Raghavachari, K.; Foresman, JB.; Cioslowski, J.; Ortiz, JV.; Baboul, AG.; Stefanov, BB.; Liu, G.; Liashenko, A.; Piskorz, P.; Komaromi, I.; Gomperts, R.; Martin, RL.; Fox, DJ.; Keith, T.; Al-

Laham, MA.; Peng, CY.; Nanayakkara, A.; Challacombe, M.; Gill, PMW.; Johnson, B.; Chen, W.; Wong, MW.; Andres, JL.; Gonzalez, C.; Head-Gordon, M.; Replogle, ES.; Pople, JA. Gaussian 98 A.11.3. Gaussian Inc; Pittsburgh, PA: 2002.

12. Hampson GC, Stosick AJ. J Am Chem Soc. 1938; 60:1814-22. 


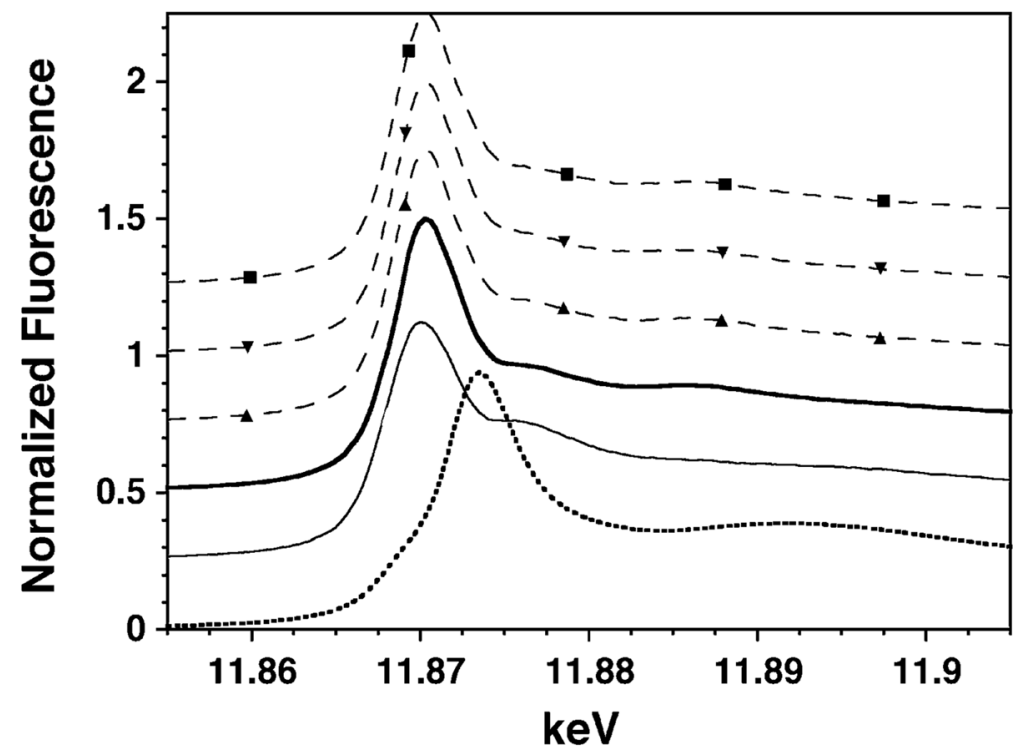

Figure 1.

Normalized XANES spectra for As samples listed in Table 1, as well as an As(V) control edge. Spectra are offset in the $y$ dimension in 0.25 increments for clarity. Spectral designations are the following: $\mathrm{Na}_{3}-\mathrm{As}(\mathrm{V}) \mathrm{O}_{4}, \cdots \bullet$; $\mathrm{As}(\mathrm{pH} 12),-; \mathrm{As}(\mathrm{pH} 7),-; \mathrm{AsSb}(1: 1),-$ $\boldsymbol{\Delta}-; \operatorname{AsSb}(1: 2),-\boldsymbol{\nabla}-; \operatorname{AsSb}(1: 4)$, 


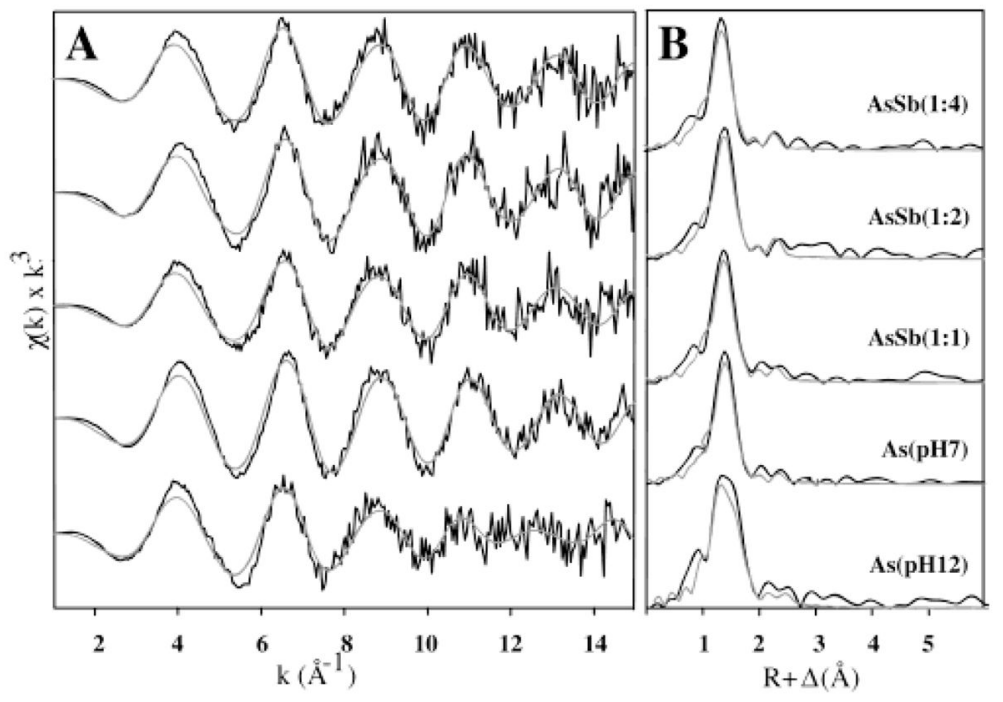

Figure 2.

Experimental and best-fit EXAFS (A) and Fourier transforms (FT) of EXAFS spectra (B) for all arsenite samples. Spectral designations for each sample are listed directly above the FT spectrum, with corresponding EXAFS directly to the left. Experimental spectra (bold lines) correspond to raw unfiltered data, while theoretical spectra (light lines) correspond to the best fit listed in Table 2 for each sample over a $k$ range of 1-15. 


\section{Table 1}

Summary of XAS Sample Names and Solution Conditions

\begin{tabular}{ccl}
\hline sample & name & soln conditns \\
\hline 1 & $\mathrm{As}(\mathrm{pH} 12)$ & $5 \mathrm{mM} \mathrm{AsNaO}_{2}$ in $\mathrm{H}_{2} \mathrm{O}$ at $\mathrm{pH}=11.8$ \\
2 & $\mathrm{As}(\mathrm{pH} 7)$ & $5 \mathrm{mM} \mathrm{AsNaO}_{2}$ in $\mathrm{H}_{2} \mathrm{O}$ at $\mathrm{pH}=7.0$ \\
3 & $\mathrm{AsSb}(1: 1)$ & $5 \mathrm{mM} \mathrm{AsNaO}$ \\
2 & $2.5 \mathrm{mM} \mathrm{K}_{2} \mathrm{Sb}_{2}$ tartrate $\bullet 3 \mathrm{H}_{2} \mathrm{O}$ in $\mathrm{H}_{2} \mathrm{O}$ at $\mathrm{pH}=7.0$ \\
4 & $\mathrm{AsSb}(1: 2)$ & $5 \mathrm{mM} \mathrm{AsNaO}_{2}+5 \mathrm{mM} \mathrm{K}_{2} \mathrm{Sb}_{2}$ tartrate $\cdot 3 \mathrm{H}_{2} \mathrm{O}$ in $\mathrm{H}_{2} \mathrm{O}$ at $\mathrm{pH}=7.0$ \\
5 & $\mathrm{AsSb}(1: 4)$ & $2.5 \mathrm{mM} \mathrm{AsNaO}_{2}+5 \mathrm{mM} \mathrm{K}_{2} \mathrm{Sb}_{2}$ tartrate $\bullet 3 \mathrm{H}_{2} \mathrm{O}$ in $\mathrm{H}_{2} \mathrm{O}$ at $\mathrm{pH}=7.0$
\end{tabular}




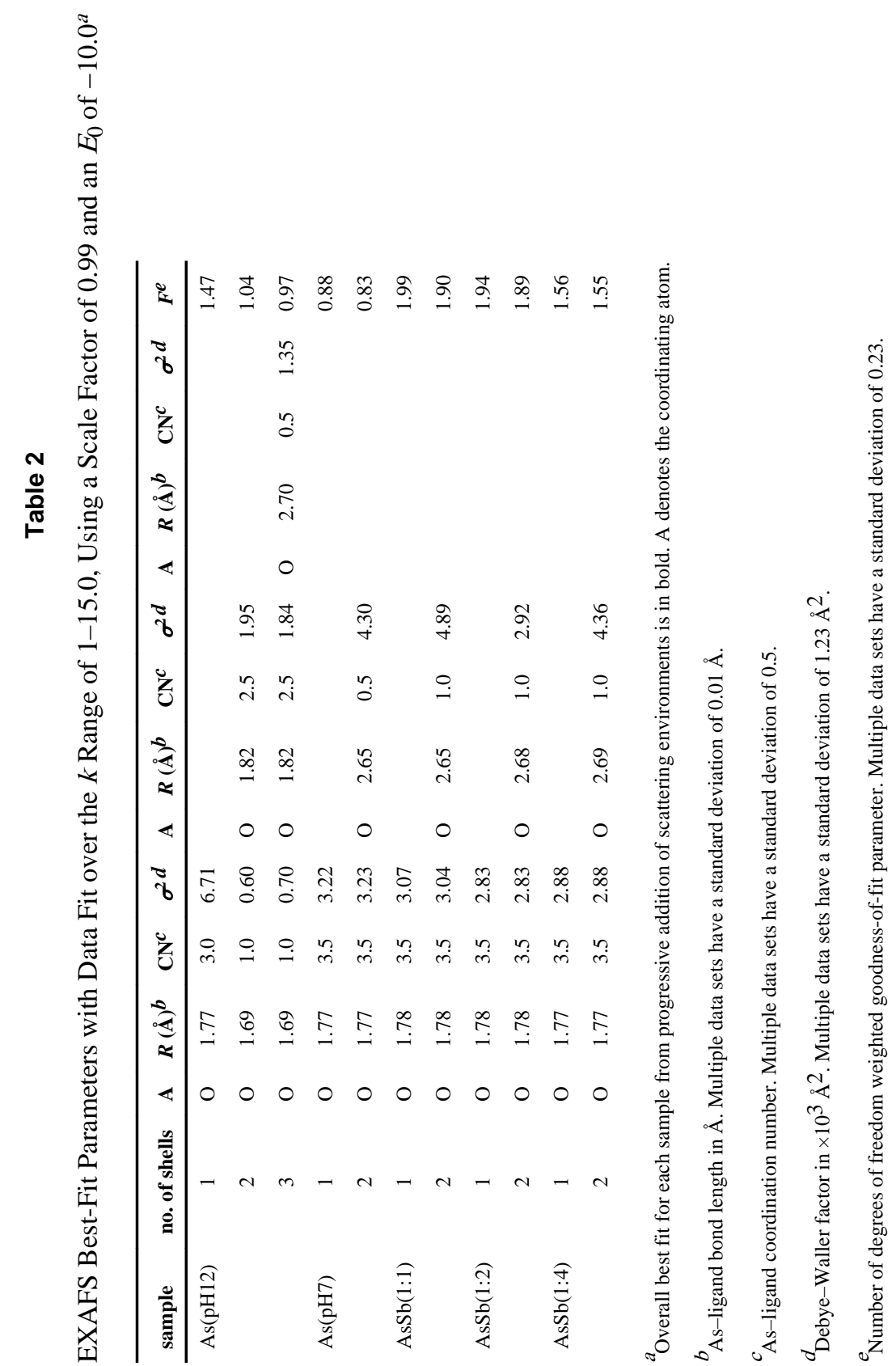


Table 3

Analysis of As(III)-Ligand Bond Distances within the Cambridge Structural Database

\begin{tabular}{lllrl}
\hline bond type & As coord geometry & $\boldsymbol{R}_{\text {ave }}(\AA)$ 1st ligand shell & $\boldsymbol{R}_{\text {ave }}(\AA)$ 2nd ligand shell & no. of entries in database \\
\hline As- ${ }^{a}$ & 3 coord & $1.77 \pm 0.03$ & 10 \\
& 4 coord & $1.81 \pm 0.02$ & 4 \\
As-As & 3 coord & $2.43 \pm 0.06$ & 21 \\
& 4 coord & $2.45 \pm 0.02$ & 16 \\
As-Sb & 3 coord & & $3.22 \pm 0.03$ \\
& 4 coord & 2.66 & \\
As-O-As ${ }^{a}$ & 3 coord & $1.78 \pm 0.01$ &
\end{tabular}

${ }^{a}$ Search criteria include oxidation state of As and a coordination sphere constructed of at least 2 oxygen atoms coordinated to one As. 


\section{Table 4}

As-O B3LYP/6-311+G* Optimized Distances in $\AA^{a}$

\begin{tabular}{|c|c|c|}
\hline structure & B3LYP/6-311+G*-RECP(As) & MP2/6-311+G**-RECP(As) \\
\hline$\left[\text { As- }-\left(\mathrm{H}_{2} \mathrm{O}\right)_{6}\right]^{3+}$ & $2.186,2.202,2.217,2.186,2.206,2.217$ & $2.172,2.172,2.195,2.195,2.203,2.203$ \\
\hline$(\mathrm{OH})_{2} \mathrm{As}-\mathrm{As}(\mathrm{OH})_{2}(\text { trans })^{b}$ & $1.822,1.822,1.822,1.822$ & \\
\hline$R$ (As-As) & 2.486 & \\
\hline \multicolumn{3}{|l|}{$\left(\mathrm{O}_{\mathrm{a}} \mathrm{H}\right)_{2} \mathrm{As}-\mathrm{O}_{\mathrm{b}}-\mathrm{As}\left(\mathrm{O}_{\mathrm{a}} \mathrm{H}\right)_{2}$} \\
\hline$R\left(\mathrm{As}-\mathrm{O}_{\mathrm{b}}\right)$ & $1.832,1.790$ & \\
\hline$R\left(\mathrm{As}-\mathrm{O}_{\mathrm{a}}\right)$ & $1.773,1.804,1.832,1.837$ & \\
\hline $\mathrm{As}(\mathrm{OH})_{3}$ & $1.808,1.809,1.809$ & $1.815,1.811,1.824$ \\
\hline $\mathrm{As}(\mathrm{OH})_{3} \cdots \mathrm{H}_{2} \mathrm{O}$ & $1.816,1.813,1.830$ & \\
\hline \multirow[t]{2}{*}{$\operatorname{As}(\mathrm{OH})_{3} \cdots\left(\mathrm{H}_{2} \mathrm{O}\right)_{3} c$} & $1.786,1.844,1.860$ & \\
\hline & $2.703,3.252,3.486$ & \\
\hline \multirow[t]{2}{*}{$\mathrm{As}(\mathrm{OH})_{3} \cdots \cdot\left(\mathrm{H}_{2} \mathrm{O}\right)_{3} d$} & & $1.792,1.794,1.838$ \\
\hline & & $2.903,3.574,3.783$ \\
\hline$\left[\mathrm{As}(\mathrm{OH})_{4}\right]^{+}$ & $1.717,1.718,1.708,1.680$ & $1.689,1.689,1.695,1.706$ \\
\hline \multirow[t]{2}{*}{$\mathrm{As}(\mathrm{OH})_{4}^{+} \cdots\left(\mathrm{H}_{2} \mathrm{O}\right)_{4}{ }^{e}$} & $1.694,1.694,1.688,1.688$ & $1.693,1.695,1.690,1.695$ \\
\hline & $3.525,3.594,3.543,3.597$ & $3.463,3.462,3.553,3.555$ \\
\hline \multicolumn{3}{|c|}{$\begin{array}{l}\text { a For some species the MP2/6-311+G** optimized geometries are reported. The optimized geometries are available upon request in } z \text {-matrix } \\
\text { format. }\end{array}$} \\
\hline \multicolumn{3}{|c|}{${ }^{b}$ Characterized as a transition state. } \\
\hline \multicolumn{3}{|l|}{$c_{\text {Singly hydrogen bonded. }}$} \\
\hline \multicolumn{3}{|c|}{$d_{\text {Doubly hydrogen bonded, starting from the previous B3LYP-optimized geometry. }}$} \\
\hline
\end{tabular}


Table 5

Final Optimized MP2/6-311+G** Geometry of the $\mathrm{As}(\mathrm{OH})_{4}{ }^{+} \bullet \bullet\left(\mathrm{H}_{2} \mathrm{O}\right)_{4}$ Complex

\begin{tabular}{rrrr}
\hline & \multicolumn{3}{c}{ coordinates (̊̊) } \\
\cline { 2 - 4 } at. no. & $\mathbf{x}$ & $\mathbf{y}$ & $\mathbf{z}$ \\
\hline 8 & 0.116474 & -0.232979 & -1.745159 \\
33 & 0.091102 & -0.300293 & 0.053385 \\
8 & 1.827574 & 0.013919 & 0.416930 \\
8 & -0.318519 & 1.445786 & 0.320199 \\
8 & 1.078973 & -0.677248 & 3.070567 \\
1 & 2.054603 & 0.965401 & 0.399040 \\
1 & 0.759687 & 0.406454 & -2.091186 \\
1 & -1.162387 & 1.686531 & -0.056154 \\
1 & 1.650130 & -0.427585 & 2.334475 \\
1 & 1.446043 & -1.501838 & 3.398534 \\
8 & 1.720623 & 2.718907 & 1.715555 \\
1 & 1.875461 & 2.182678 & 2.499404 \\
1 & 0.963586 & 2.310310 & 1.273541 \\
8 & -1.780926 & -1.340935 & -3.576903 \\
1 & -2.102781 & -2.116251 & -3.098345 \\
1 & -1.112140 & -0.967704 & -2.985241 \\
8 & -2.732810 & -0.811332 & -0.536807 \\
1 & -3.251479 & -0.965730 & 0.259916 \\
1 & -3.363449 & -0.722510 & -1.260633
\end{tabular}

